\title{
Response to Letter to the Editor: Impact of Bariatric Surgery on Outcomes of Patients with Sickle Cell Disease: a Nationwide Inpatient Sample Analysis, 2004-2014
}

\author{
Thomas R. McCarty ${ }^{1} \cdot$ Prabin Sharma $^{1,2} \cdot$ Siddhartha Yadav $^{3} \cdot$ Julius N. Ngu $^{4} \cdot$ Basile Njei $^{5}$ (D) \\ Published online: 23 May 2019 \\ (C) Springer Science+Business Media, LLC, part of Springer Nature 2019
}

Dear Editor,

We thank the authors of this letter to the editor for their thoughtful insights and comments regarding our recent findings concerning the impact of bariatric surgery on outcomes of patients with sickle cell disease (SCD) [1]. The results of our study suggest patients with SCD and bariatric surgery have overall lower rates of vaso-occlusive crises with no difference in mortality. While these authors correctly acknowledge obesity is not common among patients with $\mathrm{SCD}$, management of patients with obesity is pivotal as previous data has shown an overall inverse relationship between body mass index (BMI) and number of admissions [2].

Based upon our study design and nature of the Nationwide Inpatient Sample database, the authors further describe that our study does not provide important information on variants of SCD. However, as they have clearly suggested, and based upon previous literature, it is highly likely that patients included in our analysis had milder forms of disease [3, 4]. Even though these patients may have milder forms of disease, the findings of this Nationwide Inpatient Sample study advocate for an important role of weight reduction surgery in the management of this specific population.

Thomas R. McCarty and Prabin Sharma are co-first authors.

Basile Njei

basile.njei@yale.edu

1 Department of Internal Medicine, Yale University School of Medicine, New Haven, CT, USA

2 Department of Internal Medicine, Yale New Haven Health-Bridgeport Hospital, Bridgeport, CT, USA

3 Hematology-Oncology Fellowship Program, Mayo Clinic, Rochester, MN, USA

4 Department of Surgery, University of Texas Medical Branch, Galveston, TX, USA

5 Section of Digestive Diseases, Yale University School of Medicine, 333 Cedar St, New Haven, CT 06520, USA
We appreciate the authors' conclusions that appear to echo the findings in our study, suggesting physicians should consider bariatric surgery as a safe and effective treatment option for specific SCD patients with morbid obesity. Although the results of our study are limited based upon database and study design constraints, we hope our study encourages future exploration on the subject of sickle cell disease and bariatric surgery.

Acknowledgments All authors approved the final version of the manuscript.

\section{Compliance with Ethical Standards}

Conflict of Interest The authors declare that they have no conflicts of interest.

Ethical Approval Statement For this type of study, formal consent is not required.

Informed Consent Statement Does not apply.

\section{References}

1. Sharma P, McCarty TR, Yadav S, et al. Impact of bariatric surgery on outcomes of patients with sickle cell disease: a nationwide inpatient sample analysis, 2004-2014. Obes Surg. 2019.

2. Farooqi MW, Hussain N, et al. Prevalence of obesity in sickle cell patients. Blood. 2014;124:4932.

3. Hall R, Gardner K, Rees DC, et al. High body mass index in children with sickle cell disease: a retrospective single-centre audit. BMJ Paediatr Open. 2018;2:e00302.

4. Mandese V, Bigi E, Bruzzi P, et al. Endocrine and metabolic complications in children and adolescents with sickle cell disease: an Italian cohort study. BMC Pediatr. 2019;19:56.

Publisher's Note Springer Nature remains neutral with regard to jurisdictional claims in published maps and institutional affiliations.

This article has not been published and is not under consideration elsewhere. 